\title{
Mechanical response of local rapid cooling by spray water on constrained steel frame structure at high temperature in fire
}

\author{
Yunchun XIA ${ }^{1, a}$ \\ ${ }^{1}$ School of Civil Engineering, Anhui Jianzhu University, Hefei, 230022, P.R. China
}

\begin{abstract}
Locally rapid cooling of spray water had strong impact on high temperature steel structure. When temperature of beam reached $600^{\circ} \mathrm{C}$ and cooling rate was more than $20^{\circ} \mathrm{C} / \mathrm{s}$, the maximum axial tension could reach more than 5 times of the originally compressive force. The compressive bending moment at joint of beam-to-column changed to tensile bending moment, and the maximum bending moment could reach above 4 times as that when heated. After rapid cooling by spray water, deflection at mid-span increased slightly.
\end{abstract}

\section{Introduction}

Steel structure had many advantages, such as high strength, light weight, good toughness, convenience in construction, so it was widely used for various constructions. However, although steel was not burning, it was poor of fire prevention. In absence of fire protection, steel structure building was extremely vulnerable to be damaged or even collapsed in fire. To effectively prevent steel structure from damage, the major method was local spray water cooling or protective coating [1-2,5-12]. When rapidly cooled by local spray water, A large thermal stress would produced because of large temperature difference and stress concentration would happened in the region of structural break, that would produced a strong impact on the stability for the structure. Therefore, when a high temperature steel structure was cooled by the wrong fire fighting water, it had not only no protection for the building, but also a strong destructive impact on the building, sometimes it might also cause stress-strain to increase rapidly, and it might lead to the building to collapse in short time.

\section{Mechanical Modelling}

The temperature field of fire and thermal property of component would change when cooled by spray water. Therefore, temperature field inside of component was nonlinear transient temperature field. To simplify mechanical and thermal analysis, this based on the following assumptions: (1) The temperature field along the length of the member is unchanged.(2) Both the element local buckling and plane deformation were omitted.(3) The influence of component stress field on the temperature field was omitted.(4) (4) The component section met the assumption of plane section.

\subsection{Modelling}

Fire happened in the middle bottom of room in the middle span. The dimension of steel frame structure was shown in Fig.1. The constraint and loading and water cooling method of the frame were shown in Fig.2.

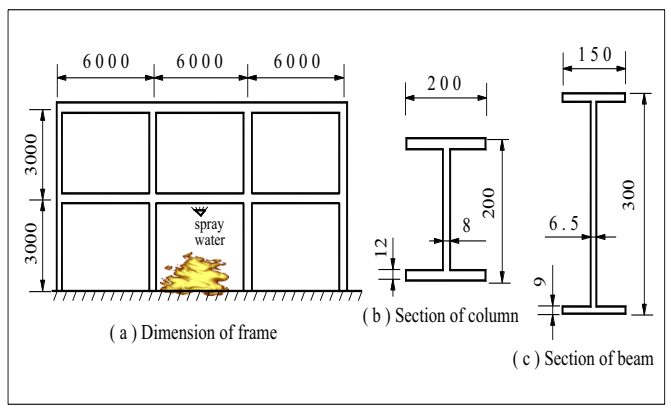

Fig.1. Calculation model of steel frame

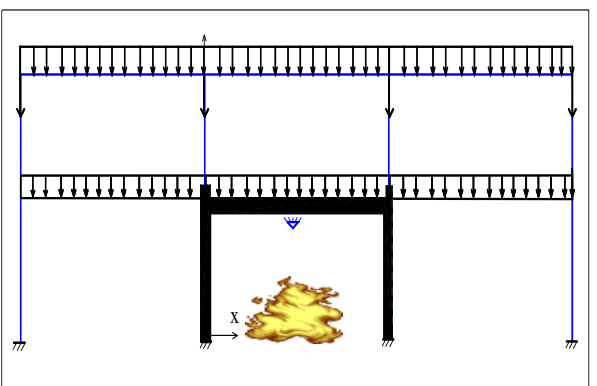

Fig.2. Constraint and loading

\subsection{Physical Parameters}

\footnotetext{
${ }^{\mathrm{a}}$ Corresponding author: author@e-mail.org
} 
The chosen steel was Q235 H-type, its physical parameters would change at high temperature. The main physical parameters at different temperature were shown in table 1.

Table 1. Physical parameters of steel at different temperature

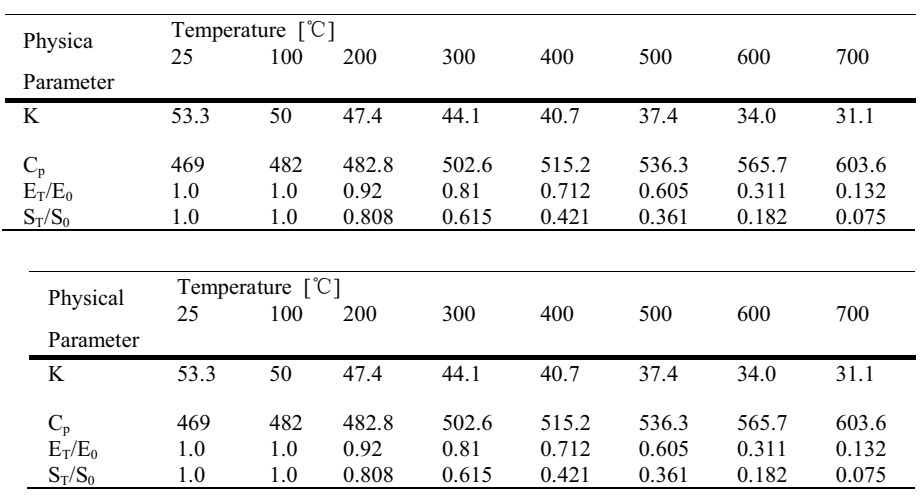

${ }^{*} \mathrm{~K}$ was the thermal conductivity $\left[\mathrm{W} /\left(\mathrm{m} .{ }^{\circ} \mathrm{C}\right)\right]$. Cp was specific heat $\left[\mathrm{J} /\left(\mathrm{kg} .{ }^{\circ} \mathrm{C}\right)\right]$. ET/E0 was the reduction factor of elastic modulus, ST/S0 was the reduction factor of relative strength.

At High temperature, Poisson's ratio of structural steel was stable, the influence of temperature on it was very small. Here, $v=0.3$. Thermal expansion coefficient $\alpha \mathrm{s}=1.41 \times 10-5 \mathrm{~m} /\left(\mathrm{m} .{ }^{\circ} \mathrm{C}\right)$, steel density $\rho=7850 \mathrm{~kg} / \mathrm{m} 3$. At ambient temperature, the yield stress fy $=278 \mathrm{~N} / \mathrm{mm} 2$, its elastic modulus $\mathrm{E}=2.102 \times 105 \mathrm{~N} / \mathrm{mm} 2$.

\section{Results and Analysis}

Steel frame was fixed by high strength bolts at bottom end, the whole steel frame was heating up according to practical fire (it was similar to the $\mathrm{HC}$ standard fire curve). After heating up to $600^{\circ} \mathrm{C}$, it was cooled by spray water. When the cooling rate was $15^{\circ} \mathrm{C} / \mathrm{s}$, the temperature distribution was shown in Fig.3. When water was sprayed until beam and column failed, Mises stress of the structure was shown in Fig. 4.

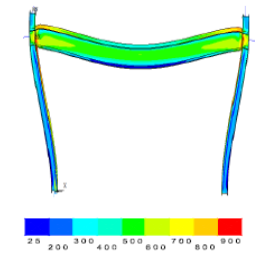

(a) $100 \mathrm{~s}$

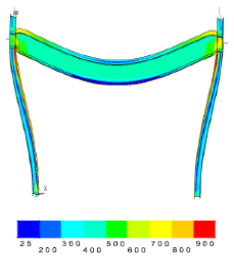

(b) $200 \mathrm{~s}$

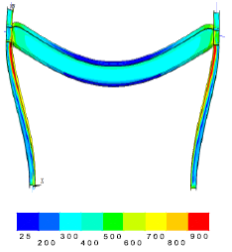

(c) $300 \mathrm{~s}$

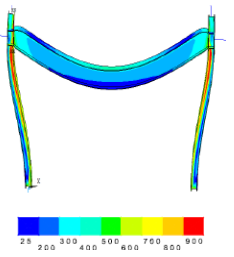

(d) $400 \mathrm{~s}$

Fig.3. The temperature distribution at fire span at different time

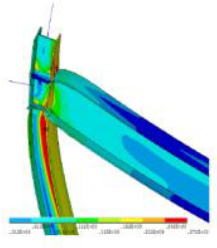

(a) $100 \mathrm{~s}$

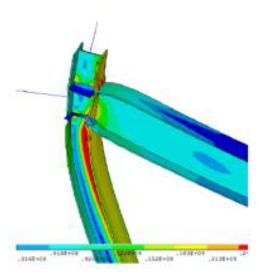

(b) $200 \mathrm{~s}$

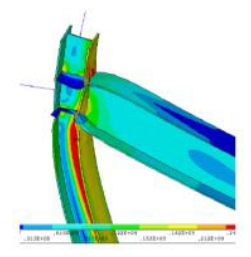

(c) $300 \mathrm{~s}$

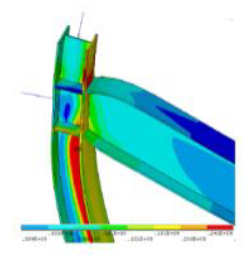

(d) $400 \mathrm{~s}$

Fig.4. Mises stress nephograms of beam and column until failed

As shown from Fig.3 to Fig.4, after high temperature steel frame was acted by spray water, its local temperature rapidly decreased, deflection at mid span of fire span increased rather than decreased, but its increase rate was limited, it had the hysteresis at beginning of 
cooling. At joint of beam-to-column, the deformation was small. However, according to Mises stress nephogram, stress increased at joints of beam-to-column, and the high stress area also increased. That was the essential difference between rapid cooling and slow cooling.

As shown in Fig.5 and Fig.6, after rapidly cooled by spray water, the deflection at mid span increased at first, and the higher the temperature of structure was, the larger the final variation of deflection at mid span was. But for column, the maximum lateral displacement gradually increased at the beginning of cooling, and the higher the temperature of structure was, the faster of the maximum lateral displacement increased, its change was also larger. After cooling for some time, the maximum lateral displacement of column slowly decreased, but it was still larger than that at beginning of cooling after it was cooled near ambient temperature.

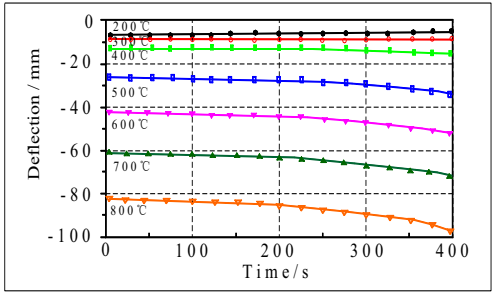

Fig.5. Deflection at mid-span

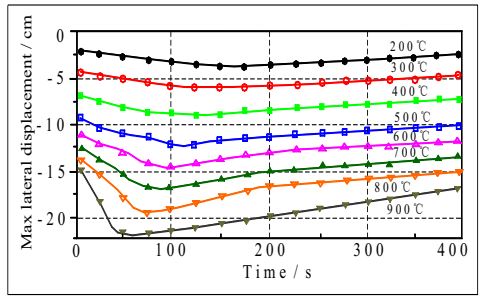

Fig.6. Max lateral displacement of bean

After the whole steel structure was heated up to different temperature, and then it was cooled by spray water. When cooling rate was $5{ }^{\circ} \mathrm{C} / \mathrm{s}, 10{ }^{\circ} \mathrm{C} / \mathrm{s}$ and $20{ }^{\circ} \mathrm{C} / \mathrm{s}$ respectively, the changes of axial forces of beam were shown in Fig. 7.

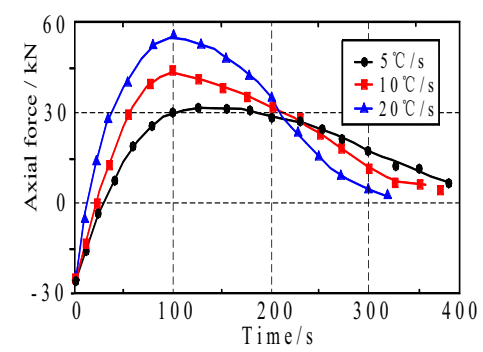

(a) Cooling from $300^{\circ} \mathrm{C}$

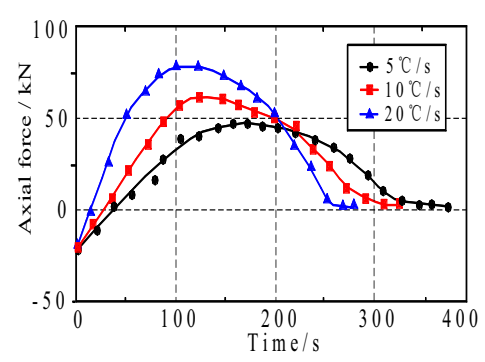

(b) Cooling from $500^{\circ} \mathrm{C}$

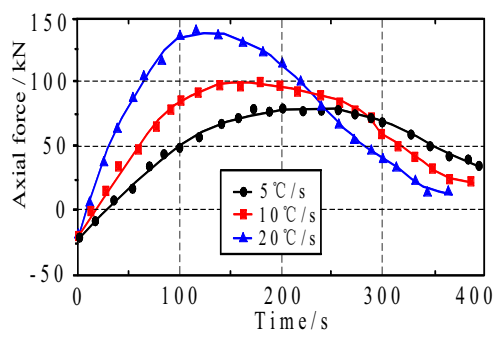

(c) Cooling from $700^{\circ} \mathrm{C}$

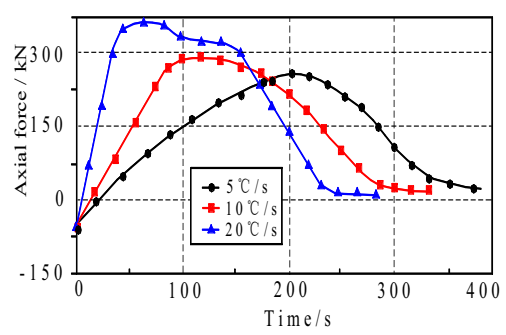

(d) Cooling from $900^{\circ} \mathrm{C}$

Fig.7. Axial forces of beam at mid-span at different cooling rate

According to Fig.7, during rapid cooling, the stress at cooling area quickly changed from compressive stress to tensile stress, and after cooled for some time, the maximum tensile stress was far larger than the maximum compressive stress produced during heating, and the maximum tensile stress increased with the increase of cooling rate. Moreover, the maximum axial tensile force increased with the increases of cooling rate and temperature of beam, especially the temperature of beam was above $600^{\circ} \mathrm{C}$, the maximum axial stress reached more than 5 times of the original compressive stress when cooling rate was at $20^{\circ} \mathrm{C} / \mathrm{s}$, the force inside of beam main was thermal stress. Therefore, the joints of beam-tocolumn could cause the joints to be destructed quickly.

After the whole structure was heated up to different temperatures and the cooling rate was $5^{\circ} \mathrm{C} / \mathrm{s}, 10^{\circ} \mathrm{C} / \mathrm{s}$ and $20^{\circ} \mathrm{C} / \mathrm{s}$ respectively, the changes of bending moment at joints of beam-to-column were shown in Fig. 8. 


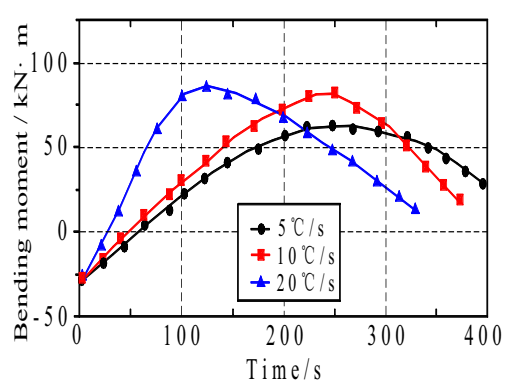

(a) Cooling from $300^{\circ} \mathrm{C}$

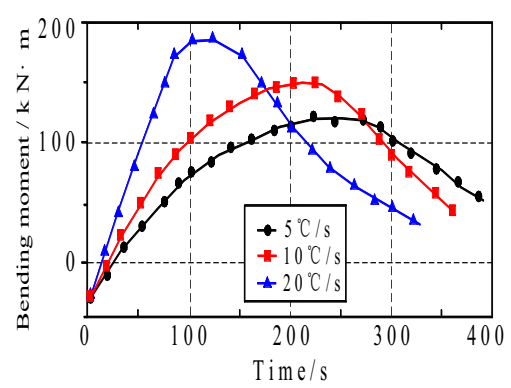

(b) Cooling from $500^{\circ} \mathrm{C}$

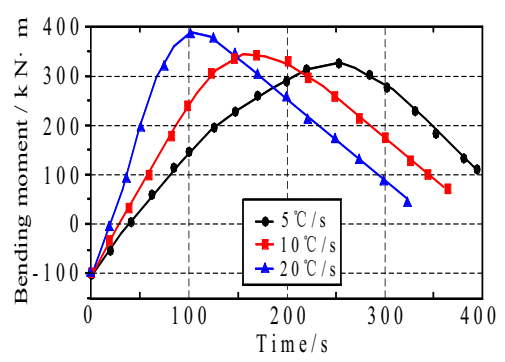

(c) Cooling from $700^{\circ} \mathrm{C}$

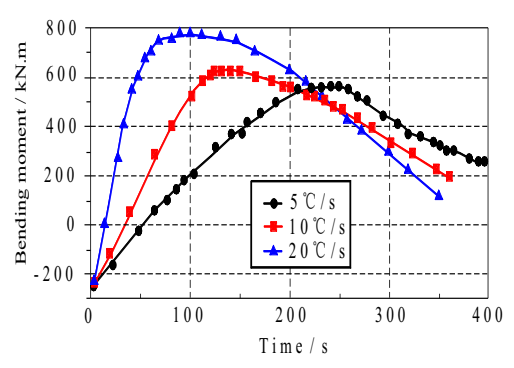

(d) Cooling from $900^{\circ} \mathrm{C}$

Fig.8. Bending moment at the joint of beam to column

Seen from Fig.8, when rapidly cooled by spray water, the bending moment at joints of beam-to-column rapidly decreased until zero, and then it changed from compressive bending moment to tensile bending moment and rapidly increased to the maximum, and the max tensile bending moment increased with the increase of cooling rate, and then it reduced. When temperature of beam was over $600^{\circ} \mathrm{C}$ and cooling rate was $20^{\circ} \mathrm{C} / \mathrm{s}$, the maximum tensile bending moment could reached above 4 times the original maximum compressive moment within just 1 minute, while the deformations of beam and column did not recover, it might lead to the instability for whole structural or collapsed. Therefore, the impact produced by rapid cooling of spray water was much larger than that of heating for high temperature steel structure buildings.

\section{Summary}

Rapid cooling of spray water had a huge impact on high temperature steel structure buildings, and the impact produced by rapid cooling of spray water was much larger than that of heating. When rapid cooled by water spray, very high level of axial force would produced inside of beam, the axial force and bending moment decreased until zero at first, and then they increased from zero and they quickly reached the maximum, the axial force increased with the increase of cooling rate, and the max axial force was much larger than that produced by heating, and it also changed from compressive force to tensile force. When the temperature of beam was over $600^{\circ} \mathrm{C}$ and cooling rate was above $20^{\circ} \mathrm{C} / \mathrm{s}$, the maximum axial tensile force could reach above 5 times the compressive force by heating. Moreover, the bending moment also increased with the increase of cooling rate, and the max bending moment also increased with the increase of cooling rate, too. When the temperature of beam was over $600^{\circ} \mathrm{C}$ and cooling rate was above $20^{\circ} \mathrm{C} / \mathrm{s}$, the maximum tensile bending moment could achieve more than 4 times that of the maximum compressive moment produced by heating. The deflection of beam at mid-span increased, and it increased with the increase of cooling rate, the maximum lateral displacement of column had a little increase within a period of cooling time, and then it slowly decreased, but it was a slightly larger than that at the end of heating.

\section{Acknowledgements}

The research work was supported by National Natural Science Foundation of China under Grant No. 51478002.

\section{References}

1. C G Bailey, D B Moore, T Lennon, The structural behavior of steel columns during a compartment fire in a multi-storey braced steel frame. Journal of constructional steel research, 55,pp.137-146,1999.

2. Rubert A and Schaumann P., Critical temperatures of steel columns exposed to fire. Fire Safety Journal, 13,pp.39-45,1988.

3. Bing Yao, Hongxue Li, JC Yang, Study on the probability distribution characteristics of actual construction fireproof performance under action of spray water, Journal Fire Science, 13,pp.209217,2004.

4. Leonard Y Cooper, The interaction of an isolated sprinkler spray and a two-layer compartment fire environment, International Journal of Heat and Mass Transfer, 38,pp.1115-1123,1995. 
5. Purkiss J A, Developments in the fire safety design of structure steelwork, Journal of Constructional Steel Research, 13,pp.149-156,1988.

6. Izzuddin B. A., Song L., An integrated adaptive environment for fire and explosion analysis of steel frames-Part II: verification and application, Journal of Construction Research, 58,pp.991-1002,2000.

7. E-Rimawi J. A., The influence of connection stiffness on the behavior of steel beams in fire, Journal of constructional steel research, 43,pp.1$12,1997$.

8. Bailey C.G et al, The influence of the thermal expansion of beams on the structural behavior of columns in steel-framed structures during a fire, Engineering Structures, 22,pp.755-766,2000.

9. Amer G.S.T. and Moor D.B., Full scale testing on composite multi-storey structure, The Structural Engineer, 72,pp.30-41,1994.

10. Wang Y.C., Lenon T. \& Moor D.B., The Behavior of Steel Frames Subject to Fire, Journal Construct. Steel Research, 35,pp.291-297,1995.

11. Franssen JM, Cooke GME, Latham DJ., Numerical Simulation of a Full Scale Fire Test on a Loaded Steel Framework, Journal of Constructional Steel Research, 51,pp.1199-1212,1995.

12. Zhao Jincheng, Application of the Direct Interaction Method for Non-Linear Analysis of Steel Frames in Fire, Fire Safety Journal, 33, pp.51-63, 2000. 